\title{
Impact of home mechanical ventilation on health-related quality of life
}

\author{
W. Windisch* on behalf of the quality of life in home mechanical \\ ventilation study group ${ }^{\#}$
}

ABSTRACT: The present multicentre study was aimed at comparably assessing the benefits and burdens associated with home mechanical ventilation (HMV).

Hospitalisation, side-effects and health-related quality of life (HRQL) were assessed 1 month and $1 \mathrm{yr}$ following HMV establishment using the Medical Outcome Study 36-Item Short-form Health Survey (SF-36; general HRQL) and the Severe Respiratory Insufficiency (SRI) Questionnaire (condition-specific HRQL).

In total, 85 (27 chronic obstructive pulmonary disease, 29 restrictive thoracic, 17 neuromuscular, nine obesity hypoventilation syndrome and three miscellaneous) out of 135 eligible patients completed the study. Mean \pm SD SRI summary scale (range 0-100) improved significantly and comparatively in all 85 patients from $49 \pm 15$ at baseline to $61 \pm 15$ at 1 month and to $61 \pm 16$ at $1 \mathrm{yr}$, but improvements of subscale scores differed amongst subgroups. SF-36 scores also improved, but the SRI was superior in detecting HRQL changes. Facial soreness and dry throat were the most commonly reported side-effects. Patients spent a mean \pm SD of $12 \pm 6$ days in hospital at baseline and $3 \pm 3$ days at each follow-up visit. Only four patients required unplanned hospitalisation.

Overall general and condition-specific health-related quality of life aspects improved following home mechanical ventilation establishment independent of the underlying disease, which, however, has an impact on changes within specific health-related quality of life domains. The need for hospitalisation is low once home mechanical ventilation is carefully established.

KEYWORDS: Chronic respiratory failure, health-related quality of life, home mechanical ventilation, hospitalisation, noninvasive ventilation, side-effects

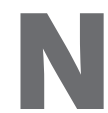
oninvasive positive pressure ventilation (NPPV) has been increasingly used to treat chronic alveolar hypoventilation $(\mathrm{CAH})$ that arises from various underlying disorders, such as restrictive thoracic disorders (RTD), neuromuscular disorders (NMD), obesity hypoventilation syndrome (OHS) and chronic obstructive pulmonary disease (COPD) [1, 2]. Healing is not possible in the vast majority of $\mathrm{CAH}$ patients who receive life-long NPPV as means of home mechanical ventilation (HMV). These patients usually suffer from end-stage disease with objectively severe limitations in daily life. Therefore, the assessment of subjectively reported health-related quality of life (HRQL) is extremely important in these severely sick patients.

Questionnaires are the most common form of assessment of HRQL in clinical trials. Disease- or condition-specific questionnaires are postulated to be more sensitive to changes than general questionnaires and, therefore, to be most appropriate for clinical trials in which specific therapeutic interventions are being evaluated [3]. There is, however, still uncertainty about how HMV influences HRQL in patients with CAH. Recently, the quality of life in home mechanical ventilation study group has developed the Severe Respiratory Insufficiency (SRI) Questionnaire which has been specifically designed to measure HRQL in patients receiving HMV [4]. This questionnaire has been shown to have high psychometric properties [4] and is capable of detecting changes in HRQL following establishment of HMV in various disorders $[5,6]$. Therefore, the SRI seems to be an appropriate instrument for clinical trials aimed at HRQL assessment in patients with different aetiologies of CAH being established on HMV.

There is increasing evidence that overall HRQL is strongly influenced by the underlying disease in patients already receiving HMV, with the best
AFFILIATIONS

${ }^{*}$ Dept of Pneumology, University

Hospital Freiburg, Freiburg,

Germany.

\#For a full list of members of the quality of life in home mechanical ventilation study group, see the

Acknowledgements section.

\section{CORRESPONDENCE}

W. Windisch

Dept of Pneumology

University Hospital Freiburg

Killianstrasse 5

D-79106 Freiburg

Germany

Fax: 497612703704

E-mail: wolfram.windisch@uniklinik-

freiburg.de

Received:

June 022007

Accepted after revision:

June 162008

STATEMENT OF INTEREST

A statement of interest for this study can be found at

www.erj.ersjournals.com/misc/

statements.shtml

European Respiratory Journal

Print ISSN 0903-1936

Online ISSN 1399-3003 
HRQL being reported in kyphoscoliosis patients and the worst in COPD $[4,7,8]$. Although controlled studies in patients with RTD and NMD do not exist, HRQL is believed to substantially increase in these patients while HMV is being instituted [7, 9]. In contrast, longitudinal studies have recorded only minor and inconsistent HRQL improvements following HMV in COPD patients [10-14]. Thus, it is suggested that the benefits of HRQL gained by HMV differ between various underlying disorders. However, this has never been addressed in a quantitative fashion.

The present multicentre study was aimed at testing the hypothesis that both general and condition-specific aspects of HRQL improve following the introduction of HMV. In addition, it was hypothesised that improvements would differ according to the underlying disorder. Finally, the burden caused by HMV with regard to hospitalisation and side-effects was also assessed.

\section{METHODS}

The current study protocol was approved by the institutional review board for human studies at the Albert-Ludwig University (Freiburg, Germany) and by local ethical committees of all participating institutions, and was performed in accordance with the ethical standards laid down in the Declaration of Helsinki, 2000. Informed, written consent was obtained from all subjects.

\section{Patients and study design}

COPD was diagnosed according to international guidelines [15]. Only NPPV-naïve and stable CAH patients who were hospitalised for elective HMV establishment on a ward specialised for NPPV were consecutively enrolled. Inclusion criteria were adopted from international guidelines [16]. Accordingly, all included patients had symptoms of $\mathrm{CAH}$, such as fatigue, dyspnoea and morning headache, in addition to physiological criteria established by guidelines [16]. Patients with acute respiratory failure $(\mathrm{pH}<7.35$ and/or two of the following criteria: increasing cough; purulent sputum; elevated leukocytes or C-reactive protein $>5 \mathrm{mg} \cdot \mathrm{dL}^{-1}$; pulmonary infiltrates on chest radiographs; or need for antibiotic treatment), those who received invasive ventilation via tracheostoma, those who were transferred for weaning from invasive ventilation or who were intubated during the preceding 3 months and those who were on any other ventilatory support prior to the present study, including continuous positive airway pressure, were excluded. Finally, patients who underwent any changes in medication at the hospital visit where HMV was established were also excluded.

Assessments were performed prior to HMV establishment in hospital, with follow-up checks occurring during short hospitalisation periods, 1 and 12 months after the establishment of HMV. No planned control visits were performed between 1 and 12 months. Duration of hospital stay was assessed for planned hospitalisation prior to HMV and at 1 and 12 months, and also for unplanned hospitalisations.

Patients received assist/control NPPV aimed at maximally decreasing carbon dioxide arterial tension $\left(\mathrm{Pa}_{1}, \mathrm{CO}_{2}\right)$ with the best tolerance possible $[5,17,18]$. Briefly, NPPV was titrated to achieve passive ventilation by gradually increasing ventilator settings until normocapnia was achieved or until a further increase of settings was not tolerated by the patient. Care was taken to make the patients comfortable. Humidification was used if necessary. In addition, factory-made nasal masks were used, but patients were switched to factory-made nasal-mouth masks in case of major leakage or insufficient ventilation. Finally, individually built masks were used for minimising leakage and for reducing pressure sores when using factorymade masks. Compliance with HMV was assessed via interviews with the patients and by the ventilator counter reading in all patients. Noncompliance was defined as stopping HMV owing to unwillingness to continue. In addition, side-effects caused by NPPV were recorded by the physician at 1 and 12 months, with the patient responding "yes" or "no". HRQL was assessed prior to HMV and at 1 and 12 months.

Measurements of daytime blood gases taken at rest from the arterialised earlobe were performed in addition to measurements of lung function [19] and mouth occlusion pressures prior to HMV and at 1 and 12 months. For maximal inspiratory mouth pressure $(P \mathrm{I}, \mathrm{max})$, the peak pressure was obtained as previously described [20]. During NPPV, further blood gas measurements were performed in the night prior to HMV and at 1 and 12 months to optimise NPPV treatment (data not shown).

The Medical Outcome Study 36-Item Short-form Health Survey (SF-36) with eight subscales and two summary measures (physical component summary (PCS) and mental component summary (MCS)) was used for the assessment of general health [21, 22]. In addition, the SRI questionnaire was administered for the assessment of specific aspects of HRQL [4]; here, one summary scale can be built from seven subscales. Self-administration was performed for HRQL assessment prior to HMV and at 1 and 12 months. Both questionnaires are suitable for HRQL assessment in patients receiving HMV and have been shown to be capable of discriminating between different diagnostic groups $[4,8]$.

\section{Statistical analysis}

Mean \pm SD values are given. Pearson product moment correlation was used for correlation analysis. A multivariate ANOVA was used to test time effects combined with group effects (e.g. diagnosis) on the dependent variables (e.g. HRQL data, physiological parameters). For HRQL, the three summary scales were used: SRI-summary scale, SF-36-PCS and SF-36-MCS. Post hoc tests (paired and unpaired t-tests, depending on comparisons) were performed if overall effects in multivariate ANOVA were $<0.05$. Group effects were restricted to patients with COPD, RTD and NMD, owing to the low case number of patients with different underlying disorders. Power analysis (GPower 3.0.8; Dept of Experimental Psychology at the Heinrich-Heine University, Dusseldorf, Germany) was performed to establish effect size for subgroup analysis.

Multivariate ANOVA was also used to compare patients who completed the study with those who dropped out. In addition, the SRI and SF-36 scales were compared (multivariate ANOVA) with regard to the ability of detecting changes in HRQL. Here, calculation was performed after standardisation of $\mathrm{z}$-values, assuming different mean score values of the scales of the different questionnaires. A p-value $<0.05$ was considered statistically significant. 


\section{RESULTS}

\section{Patients}

A total of 137 patients receiving HMV from nine German centres specialising in NPPV were recruited (fig. 1): Evangelisches Krankenhaus Göttingen-Weende e.V. (Lenglern; n=31), Asklepios Fachkliniken München-Gauting (Gauting; $n=23$ ), Krankenhaus Großhansdorf (Großhansdorf; $n=22$ ), Universitätsklinik Freiburg (Freiburg; n=21), Krankenhaus Donaustauf (Donaustauf; $\mathrm{n}=10$ ), Universitätsklinik Magdeburg (Magdeburg; $\mathrm{n}=10)$, Fachkrankenhaus Kloster Grafschaft/Schmallenberg (Schmallenburg; $n=8$ ), Lungenfachklinik Heckeshorn/Berlin (Berlin; $n=6$ ) and Städtisches Krankenhaus Martha-Maria Halle-Dölan (Halle; $n=6$ ). Two patients were excluded and 135 patients were included (fig. 1). All patients were stable at enrolment (mean \pm SD pH $7.40 \pm 0.04$ ). Mean \pm SD age was comparable in patients who completed the study and those who did not: $61 \pm 11$ versus $62 \pm 9$ yrs (COPD), $63 \pm 13$ versus $61 \pm 14$ yrs (RTD), $53 \pm 15$ versus $64 \pm 14$ yrs (NMD) and $59 \pm 6$ versus $53 \pm 14$ yrs (OHS), respectively. The same was true for BMI: $28 \pm 9$ versus $29 \pm 8 \mathrm{~kg} \cdot \mathrm{m}^{-2}$ (COPD), $27 \pm 6$ versus $26 \pm 5 \mathrm{~kg} \cdot \mathrm{m}^{-2}$ (RTD), $26 \pm 8$ versus $24 \pm 3 \mathrm{~kg} \cdot \mathrm{m}^{-2}$ (NMD) and $40 \pm 7$ versus $42 \pm 1 \mathrm{~kg} \cdot \mathrm{m}^{-2}$ (OHS), respectively. The following results refer to the 85 patients who completed the study, if not otherwise indicated.

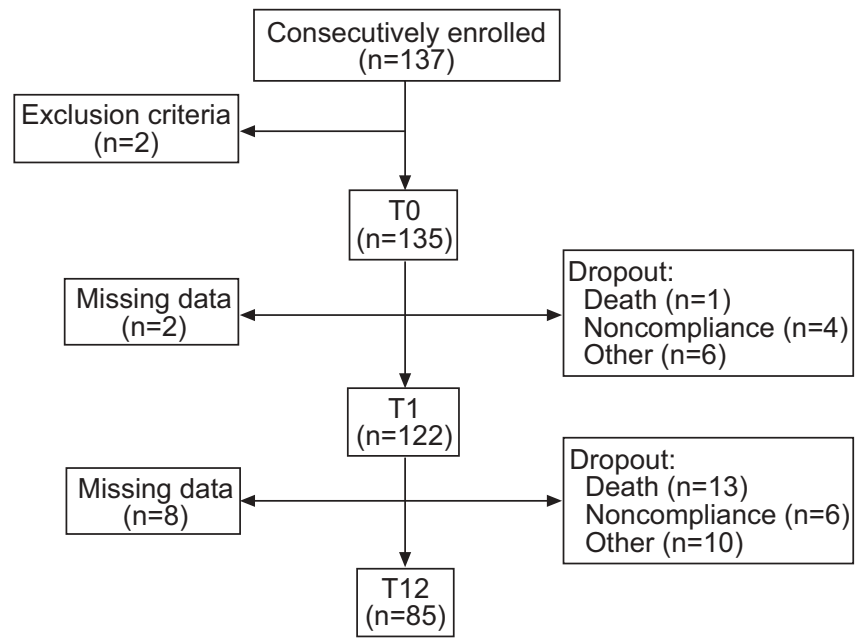

FIGURE 1. Flow diagram of patients who completed 1 yr of home mechanical ventilation (HMV) and those who discontinued. Two patients were excluded who had acute respiratory failure. Underlying disease in the patient who died before the prior to HMV (T0) timepoint and 1 month (T1): restrictive thoracic disorders (RTD), $\mathrm{n}=1$. Underlying diseases in patients who died between $\mathrm{T} 1$ and 12 months (T12): amyotrophic lateral sclerosis (ALS), $n=6$; neuromuscular disorders (NMD) other than ALS, $n=3$; chronic obstructive pulmonary disease (COPD), $n=3$; and RTD, $\mathrm{n}=1$. Median (range) time to death was 19 (3-46) weeks. Underlying diseases in patients with noncompliance between T0 and T1: ALS, $n=1 ;$ RTD, $n=1$; and obesity hypoventilation syndrome $(\mathrm{OHS}), \mathrm{n}=2$. Underlying diseases in patients with noncompliance between T1 and T12: ALS, $n=1$; COPD, $n=2$; RTD, $n=1$; and $\mathrm{OHS}, \mathrm{n}=2$. Median time to noncompliance was 4 (1-26) weeks. Other reasons for dropping out between T0 and T1: three patients were lost to follow-up; two patients continued HMV, but refused regular control visits; and one patient moved to another area. Other reasons for dropping out between T1 and T12: six patients were lost to follow-up; three patients continued HMV, but refused regular control visits; and one patient moved to another area.

\section{NPPV}

In total, 65 (76.5\%) patients received pressure-limited NPPV (table 1 ) and $20(23.5 \%)$ patients received volume-limited NPPV. Passive humidification was applied in 50 (59\%) patients using a heat and moisture exchanger, and active humidification was applied in six (7\%) patients using a humidifier. In total, $31(36.5 \%)$ patients received supplementary oxygen in addition to NPPV. Interfaces were used as follows: factorymade nasal masks $(\mathrm{n}=33 ; 39 \%)$; factory-made nasal-mouth masks ( $n=9 ; 11 \%)$; individually built nasal masks $(n=42 ; 49 \%)$; and individually built nasal-mouth masks $(n=1 ; 1 \%)$.

At 1 month (T1), patients claimed to use the ventilator $7.2 \pm 2.1 \mathrm{~h}$ per day, and the counter indicated $6.5 \pm 2.1 \mathrm{~h}$ of HMV per day $(\mathrm{r}=0.82, \mathrm{p}<0.001)$. Accordingly, $8.0 \pm 2.4 \mathrm{~h}$ (patient) and $7.3 \pm 2.7 \mathrm{~h}$ (counter) of HMV were indicated at 12 months (T12) $(\mathrm{r}=0.86, \mathrm{p}<0.001)$. Ventilator settings only slightly and nonsignificantly changed during the study period, with the exception of an increase of the inspiratory positive airway pressure in RTD and NMD patients: $20.5 \pm 3.8$ (prior to $\mathrm{HMV}$ (T0); $2.00 \pm 0.37 \mathrm{kPa})$ to $21.5 \pm 4.0 \mathrm{cmH}_{2} \mathrm{O} \quad(\mathrm{T} 12$;

\section{TABLE 1 Demographics, lung function parameters, mouth occlusion pressures and ventilator settings at the time of establishment of home mechanical ventilation in patients who completed the study}

\begin{tabular}{|c|c|c|c|c|}
\hline & COPD & RTD $\#$ & NMD & OHS \\
\hline Subjects n & 27 & 29 & 17 & 9 \\
\hline Females \% & 26 & 66 & 29 & 23 \\
\hline Age yrs & $61 \pm 11$ & $63 \pm 13$ & $53 \pm 15$ & $59 \pm 6$ \\
\hline BMI $\mathbf{k g} \cdot \mathrm{m}^{-2}$ & $28 \pm 9$ & $27 \pm 6$ & $26 \pm 8$ & $40 \pm 7$ \\
\hline FEV $1 \%$ pred & $34 \pm 14$ & $39 \pm 14$ & $49 \pm 23$ & $57 \pm 19$ \\
\hline FVC \% pred & $50 \pm 19$ & $39 \pm 16$ & $46 \pm 20$ & $50 \pm 11$ \\
\hline FEV1/FVC \% & $50 \pm 14$ & $83 \pm 9$ & $83 \pm 13$ & $79 \pm 15$ \\
\hline TLC \% pred & $105 \pm 30$ & $61 \pm 17$ & $75 \pm 24$ & $79 \pm 23$ \\
\hline$P_{0.1} \mathrm{kPa}$ & $0.41 \pm 0.17$ & $0.51 \pm 0.26$ & $0.25 \pm 0.14$ & $0.41 \pm 0.05$ \\
\hline$P \mathrm{l}, \max \mathrm{kPa}$ & $4.2 \pm 1.4$ & $3.7 \pm 1.6$ & $3.7 \pm 1.8$ & $5.6 \pm 2.7$ \\
\hline IPAP $^{+} \mathbf{c m H}_{2} \mathrm{O}$ & $25 \pm 6$ & $20 \pm 4$ & $19 \pm 4$ & $23 \pm 3$ \\
\hline $\mathrm{EPAP}^{+} \mathrm{cmH}_{2} \mathrm{O}$ & $1 \pm 2$ & $3 \pm 2$ & $1 \pm 2$ & $1 \pm 2$ \\
\hline$f^{+}$breaths $\cdot \min ^{-1}$ & $18 \pm 3$ & $19 \pm 4$ & $18 \pm 4$ & $19 \pm 2$ \\
\hline
\end{tabular}

Data are presented as mean $\pm \mathrm{SD}$, unless otherwise stated. Data from patients with miscellaneous disorders (silicosis, $n=1$; traumatic, $n=1$; unclassified, $n=1$ ) are not shown. COPD: chronic obstructive pulmonary disease; RTD: restrictive thoracic diseases; NMD: neuromuscular disorders; OHS: obesity hypoventilation syndrome; BMI: body mass index; FEV1: forced expiratory volume in one second; \% pred: \% predicted; FVC: forced vital capacity; TLC: total lung capacity; P0.1: mouth occlusion pressure; PI,max: maximal inspiratory mouth pressure; IPAP: inspiratory positive airway pressure; EPAP: expiratory positive airway pressure; $f R$ : respiratory frequency. ${ }^{*}$ : idiopathic kyphoscoliosis $(n=20)$, post tuberculosis sequelae $(n=7)$, ankylosing spondylitis $(n=1)$ and scoliosis following severe callosity $(n=1) ; \bullet$ : amyotrophic lateral sclerosis $(n=6)$, Duchenne muscular dystrophy $(n=5)$, previous poliomyelitis $(n=2)$, bilateral diaphragmatic paralysis $(n=2)$, multiple sclerosis $(n=1)$ and polyneuropathy $(n=1)$; $^{+}$: ventilator settings given for patients receiving pressure-limited noninvasive positive-pressure ventilation: COPD $(n=16), \operatorname{RTD}(n=21), N M D$ $(n=17)$ and $\mathrm{OHS}(n=6) .1 \mathrm{cmH}_{2} \mathrm{O}=0.0978 \mathrm{kPa}$ 

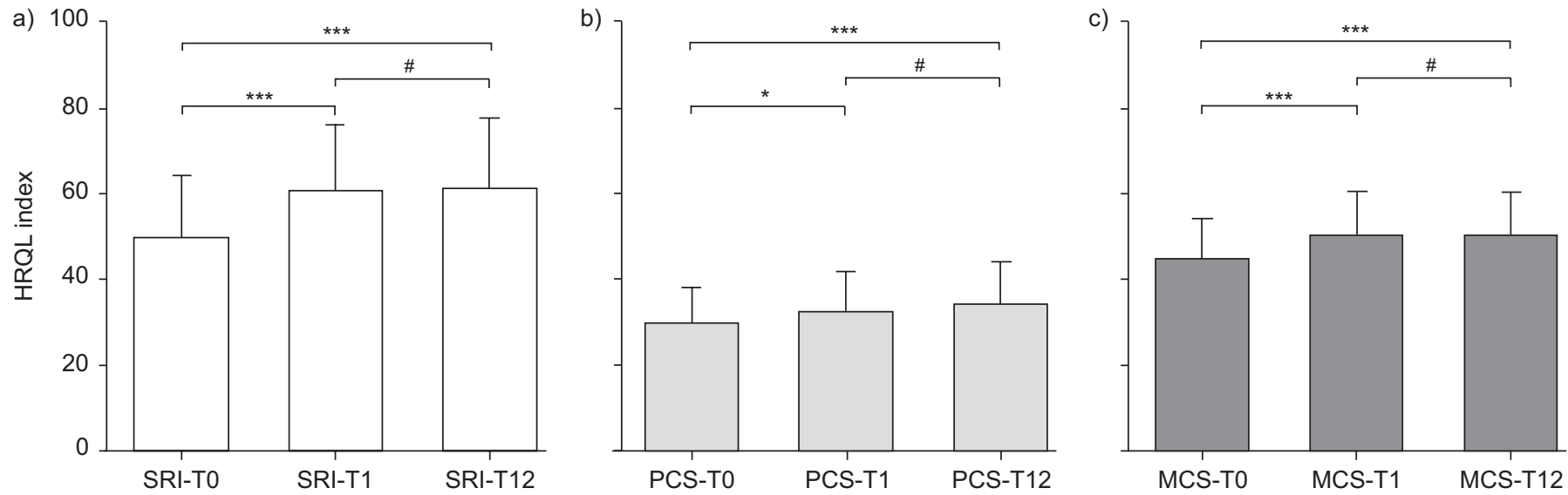

FIGURE 2. a) Summary score of Severe Respiratory Insufficiency (SRI) Questionnaire, b) physical component summary (PCS) of the Medical Outcome Survey 36-Item Short-form Health Survey (SF-36), and c) mental component summary (MCS) of the SF-36 in patients with chronic hypercapnic respiratory failure prior (T0) to home mechanical ventilation (HMV), and 1 month (T1) and 12 months (T12) following the institution of HMV ( $n=85)$. Higher values indicate better health-related quality of life (HRQL).

\#: nonsignificant; ${ }^{*}: p<0.05 ;{ }^{* *}: p<0.001$

$2.10 \pm 0.39 \mathrm{kPa} ; \mathrm{p}<0.05)$ and $19.3 \pm 4.0(\mathrm{~T} 0 ; 1.89 \pm 0.39 \mathrm{kPa})$ to $21.2 \pm 4.6 \mathrm{cmH}_{2} \mathrm{O}(\mathrm{T} 12 ; 2.07 \pm 0.45 \mathrm{kPa} ; \mathrm{p}<0.001)$, respectively.

\section{Physiological parameters}

Physiological parameters at baseline were not different in patients who completed the study compared with those who did not. For example, mean $\pm S \mathrm{SD}$ forced expiratory volume in one second (FEV1) was $34 \pm 14$ versus $31 \pm 15 \%$ predicted (COPD), $39 \pm 14$ versus $32 \pm 11 \%$ pred (RTD) and $49 \pm 23$ versus $48 \pm 17 \%$ pred (NMD), respectively; mean \pm SD total lung capacity (TLC) was $105 \pm 30$ versus $112 \pm 22 \%$ pred (COPD), $61 \pm 17$ versus $61 \pm 17 \%$ pred (RTD) and $75 \pm 24$ versus $75 \pm 11 \%$ pred (NMD), respectively; mean $\pm \mathrm{SD} P \mathrm{~Pa}_{1} \mathrm{CO}_{2}$ was $58.6 \pm 9.3 \mathrm{mmHg}(7.79 \pm 1.24 \mathrm{kPa})$ versus $58.7 \pm 7.0 \mathrm{mmHg} \quad(7.81 \pm 0.93 \mathrm{kPa} ; \quad$ COPD $), \quad 51.5 \pm 8.4 \mathrm{mmHg}$ $(6.85 \pm 1.12 \mathrm{kPa})$ versus $54.6 \pm 3.8 \mathrm{mmHg}(7.26 \pm 0.505 \mathrm{kPa}$; RTD $)$ and $52.4 \pm 10.4 \mathrm{mmHg}(6.97 \pm 1.38 \mathrm{kPa})$ versus $49.2 \pm 14.0 \mathrm{mmHg}$
$(6.54 \pm 1.86 \mathrm{kPa} ; \mathrm{NMD})$, respectively; mean $\pm \mathrm{SD} P \mathrm{I}, \max$ was $4.2 \pm 1.4$ versus $5.4 \pm 2.5 \mathrm{kPa}$ (COPD), $3.7 \pm 1.6$ versus $3.6 \pm 0.3 \mathrm{kPa}$ (RTD) and $3.7 \pm 1.8$ versus $3.2 \pm 1.2 \mathrm{kPa}(\mathrm{NMD})$, respectively. Data for OHS were missing. Baseline data are shown in table 1. There were slight but significant increases in lung function parameters at T12 in COPD and RTD patients, but not in NMD and OHS. FEV1: $34 \pm 14$ to $41 \pm 23 \%$ pred (COPD; $p<0.01$ ) and $39 \pm 14$ to $45 \pm 15 \%$ pred (RTD; $\mathrm{p}<0.01$ ), respectively; forced vital capacity (FVC): $50 \pm 19$ to $63 \pm 24 \%$ pred (COPD; $p<0.001)$ and $39 \pm 16$ to $48 \pm 14 \%$ pred (RTD; $p<0.01$ ), respectively; TLC: $105 \pm 30$ to $114 \pm 27 \%$ pred $(\mathrm{p}<0.01)$ for COPD patients, but the change was nonsignificant in RTD. FEV1/FVC did not change significantly. $P \mathrm{I}$,max increased in COPD (RTD) patients from $4.2 \pm 1.4(3.7 \pm 1.6)$ to $4.9 \pm 2.3(4.6 \pm 2.0) \mathrm{kPa}$ after $1 \mathrm{yr}$ of treatment $(\mathrm{p}<0.05$ and $\mathrm{p}<0.01$, respectively). Changes in blood gases are provided in table 2 .

TABLE 2 Blood gas analysis according to the underlying disease prior (TO) to home mechanical ventilation (HMV), and 1 month (T1) and 12 months (T12) following the institution of HMV in patients who completed the study

\begin{tabular}{|c|c|c|c|c|}
\hline & Disease categories & то & T1 & T12 \\
\hline \multirow[t]{3}{*}{$\mathrm{Pa}, \mathrm{CO}_{2} \mathrm{mmHg}$} & COPD & $58.6 \pm 9.3$ & $45.9 \pm 4.8^{\star \star \star}$ & $44.5 \pm 7.2^{\star \star \star}$ \\
\hline & NMD & $52.4 \pm 10.4$ & $44.0 \pm 4.9^{\star \star \star}$ & $41.3 \pm 7.4^{\star \star \star}$ \\
\hline & $\mathrm{OHS}$ & $53.5 \pm 6.6$ & $41.4 \pm 3.3^{\star \star}$ & $39.8 \pm 5.0^{* *}$ \\
\hline \multirow[t]{2}{*}{$\mathrm{Pa}, \mathrm{O}_{2} \mathrm{mmHg}$} & COPD & $49.0 \pm 6.0$ & $62.0 \pm 8.9^{\star \star \star}$ & $60.9 \pm 8.7^{\star \star \star}$ \\
\hline & $\mathrm{OHS}$ & $60.6 \pm 4.9$ & $59.6 \pm 3.9$ & $64.1 \pm 7.0$ \\
\hline \multirow[t]{4}{*}{ Bicarbonate $\mathrm{mmol} \cdot \mathrm{L}^{-1}$} & COPD & $33.3 \pm 4.3$ & $28.7 \pm 5.5^{\star \star}$ & $27.7 \pm 5.8^{\star \star *}$ \\
\hline & RTD & $30.4 \pm 8.7$ & $27.7 \pm 4.8^{\star}$ & $27.8 \pm 2.7$ \\
\hline & NMD & $29.2 \pm 4.7$ & $26.7 \pm 2.9$ & $25.6 \pm 2.3^{*}$ \\
\hline & $\mathrm{OHS}$ & $31.6 \pm 3.6$ & $27.4 \pm 2.3^{*}$ & $25.9 \pm 2.9^{*}$ \\
\hline
\end{tabular}

Data are presented as mean $\pm \mathrm{SD}$. $\mathrm{Pa}, \mathrm{CO}_{2}$ : carbon dioxide arterial tension; $\mathrm{Pa}, \mathrm{O}_{2}$ : arterial oxygen tension; $\mathrm{COPD}$ : chronic obstructive pulmonary disease; RTD: restrictive thoracic diseases; NMD: neuromuscular disorders; OHS: obesity hypoventilation syndrome. $*$ : $p<0.05$; $* *: p<0.01 ; * \star *: p<0.001$, compared with T0. $1 \mathrm{mmHg}=0.133 \mathrm{kPa}$. 


\section{Hospitalisation}

In order to become familiarised with NPPV, it was necessary for patients to complete a mean stay in hospital of $12 \pm 6$ days. In contrast, patients spent only $3 \pm 3$ days in hospital for each of the routinely planned control visits. Only four patients required additional unplanned hospital admissions: for exacerbation of COPD in two patients, with 6 and 13 days in hospital, respectively; for aspiration in one amyotrophic lateral sclerosis (ALS) patient (two days in hospital); and for mask problems in another ALS patient (four days in hospital).

\section{$H R Q L$}

Both general (SF-36) and disease-specific (SRI) aspects of HRQL improved in patients with $\mathrm{CAH}$ following the institution of HMV; in the present study, HRQL had already improved following 1 month of HMV and subsequently remained stable at this elevated level during the following year (fig. 2). Multivariate ANOVA on HRQL summary scales multiplied by time revealed significant effects over time $(\mathrm{F}=32.80, \mathrm{p}<0.0001)$ and the interaction of HRQL summary scales over time $(\mathrm{F}=11.56$, $\mathrm{p}<0.0001$ ). Multivariate ANOVA on diagnostic groups multiplied by HRQL summary scales multiplied by time revealed a significant effect over time $(\mathrm{F}=22.22, \mathrm{p}<0.001)$. However, overall differences in patient groups were not significant $(F=0.11$, $\mathrm{p}=0.89$ ) and improvements in HRQL summary measures were not dependent on the underlying disease $(F=0.62, p=0.65)$. Here, power analysis with an achieved sensitivity of 0.8 indicated that the present study could detect even small differences with effect sizes of 0.3 with regard to a middle correlation of the HRQL measures of 0.5 .
In contrast, changes in HRQL were disease dependent with regard to the single scales of the SRI and SF-36 (tables 3 and 4). In particular, significant improvements in physical functioning were evident only in COPD and RTD patients. In contrast, most improvements in attendant symptoms and sleep were observed in NMD and OHS patients, although all other patients improved as well. Importantly, improvements in psychological well-being and social functioning after $1 \mathrm{yr}$ of HMV were highly significant in COPD, RTD and OHS patients, but were nonsignificant in NMD patients. All patients also showed substantial improvements in respiratory complaints and anxieties, although RTD and OHS patients had the highest increases in anxiety scores. Social relationships were the only SRI subscale in which no improvements were gained. However, this subscale already showed the highest scores, even at T0, indicating less impairment.

The overall improvements in HRQL were different when summary scales of the SRI and the SF-36 were compared. Even when $z$-value standardisation of the scale scores was performed, the improvements gained by the summary score of the SRI were significantly more evident when compared with the PCS of the SF-36 (multivariate ANOVA: $F=2.60$, $p=0.037$ ). Although both summary measures of the SF-36 improved significantly in the total group $(n=85)$ of patients (fig. 2), this was not valid for the single groups of patients (table 3). In addition, improvements of SF-36 subscale scores in the three different patient groups were inconsistent, with eight, four and one subscales showing improvements at T12 in RTD, COPD and NMD patients, respectively.

\begin{tabular}{|c|c|c|c|c|c|c|c|c|c|c|}
\hline TABLE 3 & \multicolumn{10}{|c|}{$\begin{array}{l}\text { Medical Outcome Survey 36-Item Short-form Health Status Survey subscales and summary measures according to the } \\
\text { underlying disease prior (T0) to home mechanical ventilation (HMV), and } 1 \text { month (T1) and } 12 \text { months (T12) following } \\
\text { the institution of HMV in patients who completed the study }\end{array}$} \\
\hline \multicolumn{11}{|l|}{ COPD } \\
\hline T12 & $39 *$ & 34 & $80 *$ & 43 & $51^{\star \star \star}$ & $69^{* *}$ & 70 & 68 & 35 & 50 \\
\hline \multicolumn{11}{|l|}{ RTD } \\
\hline TO & 24 & 7 & 52 & 35 & 37 & 64 & 41 & 56 & 28 & 45 \\
\hline $\mathrm{T} 1$ & $33^{*}$ & $23^{\star \star \star}$ & $65^{\star \star}$ & $49^{\star}$ & $49^{* *}$ & $79^{\star \star \star}$ & $51^{*}$ & 63 & 33 & 49 \\
\hline T12 & $40^{* * *}$ & $38^{* * *}$ & $63^{*}$ & $47^{* *}$ & $51^{* *}$ & $83^{\star \star \star}$ & $58^{\star \star \star}$ & $66^{*}$ & 35 & 50 \\
\hline \multicolumn{11}{|l|}{ OHS } \\
\hline TO & 29 & 6 & 59 & 31 & 25 & 58 & 17 & 55 & 30 & 37 \\
\hline $\mathrm{T} 1$ & $45^{*}$ & 39 & 46 & 42 & $49^{*}$ & 61 & $59^{*}$ & 59 & 34 & 45 \\
\hline T12 & $50 *$ & $46^{*}$ & 65 & $51^{\star \star}$ & $49 *$ & 72 & $50^{*}$ & $67^{\star}$ & $38^{*}$ & $46^{*}$ \\
\hline
\end{tabular}

PCS: physical component summary; MCS: mental component summary; COPD: chronic obstructive pulmonary disease; RTD: restrictive thoracic diseases; NMD: neuromuscular disorders; OHS: obesity hypoventilation syndrome. All scales range $0-100$, with higher values indicating better health-related quality of life. *: $p<0.05$; **: $p<0.01 ;{ }^{* * *}: p<0.001$, compared with T0. 


\begin{tabular}{|c|c|c|c|c|c|c|c|c|}
\hline $\begin{array}{l}\text { TABLE } 4 \\
\text { Disease } \\
\text { categories }\end{array}$ & \multicolumn{8}{|c|}{$\begin{array}{l}\text { Subscales and summary scale of the Severe Respiratory Insufficiency Questionnaire according to the underlying } \\
\text { disease prior (T0) to home mechanical ventilation (HMV), and } 1 \text { month (T1) and } 12 \text { months (T12) following the institution } \\
\text { of HMV in patients who completed the study }\end{array}$} \\
\hline \multicolumn{9}{|l|}{ COPD } \\
\hline T1 & $56^{\star \star \star}$ & $45^{\star \star \star}$ & $61^{\star \star \star}$ & 73 & $57^{\star \star \star *}$ & $66^{* \star *}$ & $54^{\star *}$ & $61^{\star \star \star}$ \\
\hline T12 & $56^{\star \star \star}$ & $49^{\star \star \star}$ & $61^{\star \star \star}$ & 70 & $54^{* *}$ & $64^{\star \star \star}$ & $55^{\star \star}$ & $60^{\star \star \star}$ \\
\hline \multicolumn{9}{|l|}{ RTD } \\
\hline TO & 48 & 38 & 49 & 73 & 47 & 57 & 53 & 52 \\
\hline $\mathrm{T} 1$ & $60 * \star \star$ & $51^{* * *}$ & $61^{* \star *}$ & 76 & $64^{* \star *}$ & $65^{* *}$ & $59^{*}$ & $62^{* \star \star}$ \\
\hline $\mathrm{T} 12$ & $63^{\star \star \star}$ & $51^{\star \star \star}$ & $60^{\star \star \star *}$ & 73 & $68^{* \star *}$ & $65^{\star *}$ & $62^{\star \star \star}$ & $64^{\star \star \star}$ \\
\hline \multicolumn{9}{|l|}{ OHS } \\
\hline TO & 42 & 44 & 36 & 69 & 33 & 52 & 51 & 46 \\
\hline T1 & $60^{*}$ & 60 & $60^{*}$ & 75 & 51 & 61 & 58 & $61^{*}$ \\
\hline T12 & $66^{\star \star}$ & 58 & $67^{\star}$ & 79 & $63^{*}$ & $71^{* *}$ & $66^{*}$ & $67^{\star \star}$ \\
\hline
\end{tabular}

COPD: chronic obstructive pulmonary disease; RTD: restrictive thoracic diseases; NMD: neuromuscular disorders; OHS: obesity hypoventilation syndrome. All scales range $0-100$, with higher values indicating better health-related quality of life. ${ }^{*}: p<0.05 ;{ }^{*}: p<0.01 ;{ }^{* \star}$ : $p<0.001$, compared with T0.

For both the summary measures of the SF-36 and the summary score of the SRI at baseline (T0), no significant differences in scores could be detected between patients who completed the 1-yr follow-up $(n=85)$ and those who did not $(n=50)$. In addition, patients who discontinued after T1 $(n=37)$ had comparable improvements in the SRI summary score and the summary measures of the SF-36 between T0 and T1 compared with those who completed the study $(n=85$; multivariate ANOVA: $\mathrm{F}=0.38, \mathrm{p}=0.69$ ).

\section{Side-effects of NPPV}

The most commonly reported side-effects at T1 in patients who completed the study were facial soreness caused by the mask $(33 \%)$ and dry throat (37\%). However, only 25 and $26 \%$ of patients who completed the study reported facial soreness and dry throat at 12 months, respectively. Side-effects of NPPV for all patients are shown in table 5. A dry throat was the most frequently reported symptom both in COPD patients (46 and $29 \%$ at $\mathrm{T} 1$ and T12, respectively) and in NMD patients (47 and $18 \%$ at $\mathrm{T} 1$ and $\mathrm{T} 12$, respectively). In contrast, nasal congestion was the most common symptom in RTD patients ( 31 and $21 \%$ at $\mathrm{T} 1$ and $\mathrm{T} 12$, respectively). Side-effects were also not particularly present in patients who dropped out after T1 compared with those who completed the study.

\section{DISCUSSION}

The major finding of the present study was that both general and condition-specific aspects of HRQL increased following HMV establishment. Importantly, substantial improvements were gained 1 month following HMV establishment, and these improvements could be maintained for the subsequent 12 months, during which time HMV was continued.
Overall improvements were similar between COPD, RTD and NMD patients. In particular, COPD patients had overall HRQL benefits gained by HMV comparable to those in patients with RTD and NMD. This was not predicted in advance. For patients with RTD and NMD, there is overwhelming evidence to suggest that physiological parameters, sleep quality, HRQL, and even survival, can all be improved by HMV $[1,7,9,16]$. In contrast, only inconsistent improvements in physiological

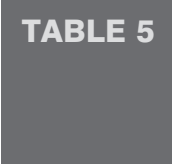

Side-effects of noninvasive positive pressure ventilation 1 month (T1) and 12 months (T12) following establishment of home mechanical ventilation in patients who completed the study

\begin{tabular}{lcc} 
Side-effect & T1 & T12 \\
\hline Dry throat $^{*}$ & $30(37)$ & $21(26)$ \\
Facial soreness $^{*}$ & $27(33)$ & $21(25)$ \\
Sleep disruption $^{*}$ & $22(27)$ & $17(20)$ \\
Nasal congestion $^{*}$ & $18(22)$ & $20(24)$ \\
Abdominal distension $^{*}$ & $18(22)$ & $11(13)$ \\
Flatulence $^{*}$ & $16(19)$ & $14(17)$ \\
Not falling asleep & $11(13)$ & $13(16)$ \\
Eye irritation $^{*}$ & $10(12)$ & $9(11)$ \\
Nasal bleeding & $6(7)$ & $2(2)$ \\
Abdominal pain $^{*}$ & $5(6)$ & $4(5)$ \\
Nausea $^{+}$ & $1(1)$ & $2(2)$ \\
Facial ulcer $^{*}$ & $1(1)$ & $0(0)$ \\
Vomiting $^{*}$ & $0(0)$ & $0(0)$ \\
\hline
\end{tabular}

Data are presented as $n(\%) .{ }^{*}: n=83 ;{ }^{\bullet}: n=82 ;{ }^{+}: n=81$ 
parameters and HRQL could be documented, and clear evidence for potential survival benefits of HMV in chronic hypercapnic COPD has not yet been established [7, 10-14, 16, 23-26]. Therefore, the current study is unique in demonstrating that both blood gases and overall HRQL improved comparatively in COPD patients and in those with restrictive diseases. One difference compared with previous studies is that NPPV was aimed at maximally decreasing $\mathrm{Pa}, \mathrm{CO}_{2}$ by using considerably higher ventilator settings, as previously established [5, 17, 18]. The drop in $\mathrm{Pa}_{2} \mathrm{CO}_{2}$ was even more evident in COPD patients, and this was due to higher values prior to HMV in COPD. Therefore, it is reasonable to suggest that the use of NPPV, which is targeted towards maximally improving alveolar ventilation, has led to comparable improvements in physical parameters and overall HRQL in COPD patients, when compared with restrictive patients.

In contrast to overall improvements in HRQL, changes in single, specific domains of HRQL with regard to SRI subscales differed significantly depending on the underlying disease. Scores of respiratory complaints significantly increased in all patients, but this led to improvements in scores of physical functioning and social functioning only in patients with COPD, RTD and, less evidently, in OHS patients, while scores in NMD remained stable, probably owing to the handicap accompanying respiratory dysfunction, i.e. weakness of the limbs. Conversely, improvements in scores of attendant symptoms and sleep were most impressive in NMD and OHS patients, but improvements in scores of psychological well-being were more evident in COPD and RTD patients. In addition, all patients showed significant improvements in scores of anxiety, but RTD patients seemed to benefit the most. This clearly indicates that the condition responsible for the development of $\mathrm{CAH}$ has a major impact on changes of specific aspects of HRQL following HMV establishment. However, since scores of the subscales respiratory complaints and attendant symptoms and sleep substantially improved in all patients, it is indicated that symptoms related to nocturnal hypoventilation are improved once HMV has been established.

Another important finding of the present study was that the SRI was superior to the SF-36 in detecting changes in HRQL. Although the two summary measures of the SF-36 revealed significant increases in scores for the total group, this was not true for the single groups of patients. This is in contrast to the SRI, where the summary scale scores increased not only in the total group, but also in the single groups. In addition, improvements of SF-36 subscale scores were inconsistent, with eight, four and only one subscales showing improvements following $1 \mathrm{yr}$ of HMV in RTD, COPD and NMD patients, respectively. Therefore, looking solely at the SF-36, HRQL benefits gained by HMV appeared to be quite small in patients with NMD compared with other patients, particularly those with RTD. However, administration of the SRI also revealed substantial improvements in overall HRQL in NMD patients compared with other disease categories. This underlines the inalienability of disease- or condition-specific instruments for reliably assessing changes in HRQL in a particular group of patients using specific treatment modalities, as in those with $\mathrm{CAH}$ receiving $\mathrm{HMV}$. The language of the original SRI is German. However, results of the Spanish version have recently been published [27] and additional versions in English, Dutch,
French, Swedish and Norwegian are in preparation (M.W. Elliott (Respiratory Medicine, St James University Hospital, Leeds UK); P. Wijkstra (University Hospital Groningen, Groningen, the Netherlands); A. Cuvelier (Pulmonary and Intensive Care Dept, Rouen University Hospital, Rouen, France); B. Midgren (Dept of Respiratory Medicine, University Hospital, Lund, Sweden); H. Markussen (Haukeland University Hospital, Bergen, Norway); personal communication, respectively) in order to make the SRI internationally available.

On average, 12 days in hospital were needed for patients to become familiarised with NPPV, and this might be related to the effort required to optimally improve blood gases and to optimise comfort during NPPV using high ventilator settings as suggested by previous investigations [13, 17]. In contrast, only 3 days in hospital were necessary for control visits in patients who continued HMV for $1 \mathrm{yr}$, and only four $(<5 \%)$ of these patients required additional, unplanned hospitalisation following careful HMV establishment. Nevertheless, the duration of the initial hospitalisation period might be judged as rather long, despite low hospitalisation duration following HMV commencement, and further studies should evaluate if shorter periods in hospital are comparably sufficient when initiating HMV. In addition, comparison of hospitalisation with the preceding year was not possible in the present study, but previous studies showed that in COPD patients the establishment of HMV resulted in fewer days in hospital and fewer hospital admissions [14, 28].

The most frequently reported side-effects were dry throat, facial soreness, nasal congestion and abdominal problems, which supports previous findings [1,29]. Although COPD and NMD patients most often reported a dry throat, while RTD patients most often complained of nasal congestion, there were no clear differences between patient groups regarding sideeffects. In addition, not falling asleep and sleep disruption were reported by 16 and $20 \%$ of patients after $1 \mathrm{yr}$ of HMV, respectively. Although scores of the SRI subscale attendant symptoms and sleep dramatically improved, particularly in NMD and OHS patients, HMV could not completely erase subjectively experienced impairments in sleep quality, or might even have caused some degree of subjective discomfort during the night. This is supported by previous sleep studies, which have clearly shown that sleep quality assessed by polysomnography was significantly improved by HMV, but did not become completely normalised [6, 24, 30, 31]. However, the link between objectively recorded and subjectively reported sleep quality needs further investigation.

There are some limitations of the current study that need to be addressed. First, additional patients were not randomised to a control group. However, there was clear evidence for compliance to HMV, which was highly effective in improving blood gases, and it is unlikely that this could be achieved without HMV. Thus, HRQL benefits are likely to be mainly attributable to HMV. In addition, blinding of patients and implementation of sham ventilation for a period of $1 \mathrm{yr}$ are extremely difficult to achieve. Moreover, controlled studies would raise ethical concerns, at least in patients with RTD and NMD, given the overwhelming evidence that HMV is indeed beneficial for these patients. Nevertheless, controlled studies in COPD patients are clearly needed to overcome the weaknesses of the uncontrolled study design. 
Secondly, it might also be argued that there is selection bias. However, patients were consecutively enrolled, and this could explain the relatively high dropout rate. In addition, patients who dropped out and those who completed had comparable demographics, physiological parameters and HRQL prior to HMV, and also had comparable HRQL improvements after 1 month of HMV. Therefore, a clear selection bias seems unlikely. In addition, a large number of statistical tests have been executed and false-positive results cannot be excluded with certainty.

Thirdly, the present study aimed to provide subgroup analysis, but subgroups remained somewhat heterogeneous and this was particularly true for patients with NMD. Therefore, the results provided for this group might not be easily transferred to each specific type of NMD, and further studies are needed to comparatively assess HMV-induced changes in HRQL in different, well-defined groups of NMD patients, particularly ALS patients. In addition, the number of patients forming the OHS group was too small to be included in the multivariate ANOVA. Changes of HRQL could, therefore, not be compared with those with other underlying diseases. Finally, further investigation is required in order to determine whether HRQL benefits are most evident in most advanced disease and whether patients with mild forms of $\mathrm{CAH}$ benefit at all.

In conclusion, the present study has demonstrated that home mechanical ventilation, when carefully established in hospital and aimed at maximally improving blood gases, seems to be capable of substantially improving general and conditionspecific aspects of health-related quality of life in patients suffering from chronic alveolar hypoventilation, with sideeffects being comparable to those reported in previous studies. Once home mechanical ventilation is carefully established in hospital, the need for further hospitalisation is low. Overall improvements in health-related quality of life are comparable in patients with chronic obstructive lung disease, restrictive thoracic disease and neuromuscular disorders. In contrast, health-related quality of life changes differ significantly between diagnostic groups in several specific domains, indicating the impact of the underlying disease on healthrelated quality of life changes. The Severe Respiratory Insufficiency Questionnaire, which specifically targets patients who are dependent on home mechanical ventilation, was superior in detecting changes in health-related quality of life when compared with the general instrument Medical Outcome Study 36-Item Short-form Health Survey. This highlights the inalienability of disease- or condition-specific instruments for reliably assessing changes in health-related quality of life in patients receiving home mechanical ventilation.

\section{ACKNOWLEDGEMENTS}

The members of the quality of life in home mechanical ventilation study group (all Germany) are as follows: T. Barchfeld (Fachkrankenhaus Kloster Grafschaft/Schmallenberg, Schmallenberg), K. Freidel (statistician; St.-Josefs Hospital Wiesbaden, Wiesbaden), J. Geiseler (Asklepios Fachkliniken München-Gauting, Gauting), F. Heinemann (Krankenhaus Donaustauf, Donaustauf), F. Kalbitz (Städtisches Krankenhaus Martha-Maria Halle-Dölan, Halle), T. Köhnlein (Universitätsklinik Magdeburg, Magdeburg), M. Raffenberg (Lungenfachklinik Heckeshorn/Berlin, Berlin), F. Petermann (Universität Bremen, Bremen), K. Schild (Ev.
Krankenhaus Göttingen-Weende e.V., Lenglern), B. Schucher (Krankenhaus Großhansdorf, Großhansdorf) and W. Windisch (Universitätsklinik Freiburg, Freiburg).

The author would like to thank S. Dieni for proofreading the manuscript prior to submission.

\section{REFERENCES}

1 Mehta S, Hill NS. Noninvasive ventilation. Am J Respir Crit Care Med 2001; 163: 540-577.

2 Lloyd-Owen SJ, Donaldson GC, Ambrosino N, et al. Patterns of home mechanical ventilation use in Europe: results from the Eurovent survey. Eur Respir J 2005; 25: 1025-1031.

3 Testa MA, Simonson DC. Assessment of quality-of-life outcomes. N Engl J Med 1996; 334: 835-840.

4 Windisch W, Freidel K, Schucher B, et al. The Severe Respiratory Insufficiency (SRI) Questionnaire: a specific measure of health-related quality of life in patients receiving home mechanical ventilation. J Clin Epidemiol 2003; 56: 752-759.

5 Windisch W, Dreher M, Storre JH, Sorichter S. Nocturnal non-invasive positive pressure ventilation: physiological effects on spontaneous breathing. Respir Physiol Neurobiol 2006; 150: 251-260.

6 Storre JH, Seuthe B, Fiechter R, et al. Average volumeassured pressure support in obesity hypoventilation: a randomized crossover trial. Chest 2006; 130: 815-821.

7 Simonds AK, Elliott MW. Outcome of domiciliary nasal intermittent positive pressure ventilation in restrictive and obstructive disorders. Thorax 1995; 50: 604-609.

8 Windisch W, Freidel K, Schucher B, et al. Evaluation of health-related quality of life using the MOS 36-Item ShortForm Health Status Survey in patients receiving noninvasive positive pressure ventilation. Intensive Care Med 2003; 29: 615-621.

9 Simonds AK. Home ventilation. Eur Respir J 2003; 22: Suppl. 47, S38-S46.

10 Elliott MW, Simonds AK, Carroll MP, Wedzicha JA, Branthwaite MA. Domiciliary nocturnal nasal intermittent positive pressure ventilation in hypercapnic respiratory failure due to chronic obstructive lung disease: effects on sleep and quality of life. Thorax 1992; 47: 342-348.

11 Meecham Jones DJ, Paul EA, Jones PW, Wedzicha JA. Nasal pressure support ventilation plus oxygen compared with oxygen therapy alone in hypercapnic COPD. Am J Respir Crit Care Med 1995; 152: 53-44.

12 Perrin C, El Far Y, Vandenbos F, et al. Domiciliary nasal intermittent positive pressure ventilation in severe COPD: effects on lung function and quality of life. Eur Respir J 1997; 10: 2835-2839.

13 Sivasothy P, Smith IE, Shneerson JM. Mask intermittent positive pressure ventilation in chronic hypercapnic respiratory failure due to chronic obstructive pulmonary disease. Eur Respir J 1998; 11: 34-40.

14 Clini E, Sturani C, Rossi A, et al. The Italian multicentre study on noninvasive ventilation in chronic obstructive pulmonary disease patients. Eur Respir J 2002; 20: 529-538.

15 Sutherland ER, Cherniack RM. Management of chronic obstructive pulmonary disease. N Engl J Med 2004; 350: 2689-2697. 
16 Clinical indications for noninvasive positive pressure ventilation in chronic respiratory failure due to restrictive lung disease, COPD, and nocturnal hypoventilation - a consensus conference report. Chest 1999; 116: 521-534.

17 Windisch W, Vogel M, Sorichter S, et al. Normocapnia during NIPPV in chronic hypercapnic COPD reduces subsequent spontaneous $\mathrm{Pa}_{1} \mathrm{CO}_{2}$. Respir Med 2002; 96: 572-579.

18 Windisch W, Kostić S, Dreher M, Virchow JC, Sorichter S. Outcome of patients with stable COPD receiving controlled noninvasive positive pressure ventilation aimed at a maximal reduction of $\mathrm{Pa}_{\mathrm{a}} \mathrm{CO}_{2}$. Chest 2005; 128: 657-662.

19 Quanjer PH, Tammeling GJ, Cotes JE, Pedersen OF, Peslin R, Yernault JC. Lung volumes and forced ventilatory flows. Report Working Party Standardization of Lung Function Tests, European Community for Steel and Coal. Official Statement of the European Respiratory Society. Eur Respir J 1993; 6: Suppl. 16, S5-S40.

20 Windisch W, Hennings E, Sorichter S, Hamm H, Criée CP. Peak or plateau maximal inspiratory mouth pressure: which is best? Eur Respir J 2004; 23: 708-713.

21 Ware JE Jr, Sherbourne CD. The MOS 36-item short-form health survey (SF-36). I. Conceptual framework and item selection. Med Care 1992; 30: 473-483.

22 Ware JE Jr, Gandek B. Overview of the SF-36 Health Survey and the International Quality of Life Assessment (IQOLA) Project. J Clin Epidemiol 1998; 51: 903-912.
23 Casanova C, Celli BRF, Tost L, et al. Long-term controlled trial of nocturnal nasal positive pressure ventilation in patients with severe COPD. Chest 2000; 118: 1582-1590.

24 Wijkstra PJ, Lacasse Y, Guyatt GH, et al. A meta-analysis of nocturnal noninvasive positive pressure ventilation in patients with stable COPD. Chest 2003; 124: 337-343.

25 Wijkstra PJ. Non-invasive positive pressure ventilation (NIPPV) in stable patients with chronic obstructive pulmonary disease (COPD). Respir Med 2003; 97: 1086-1093.

26 Hill NS. Noninvasive ventilation for chronic obstructive pulmonary disease. Respir Care 2004; 49: 72-89.

27 Lopez-Campos JL, Failde I, Jiménez AL, et al. Health-related quality of life of patients receiving home mechanical ventilation: the Spanish version of the severe respiratory insufficiency questionnaire. Arch Bronconeumol 2006; 42: 588-593.

28 Janssens JP, Derivaz S, Breitenstein E, et al. Changing patterns in long-term noninvasive ventilation: a 7 -year prospective study in the Geneva Lake area. Chest 2003; 123: 67-79.

29 Leger P, Bedicam JM, Cornette A, et al. Nasal intermittent positive pressure ventilation. Long-term follow-up in patients with severe chronic respiratory insufficiency. Chest 1994; 105: 100-105.

30 Schönhofer B, Köhler D. Effect of non-invasive mechanical ventilation on sleep and nocturnal ventilation in patients with chronic respiratory failure. Thorax 2000; 55: 308-313.

31 Gonzalez MM, Parreira VF, Rodenstein DO. Non-invasive ventilation and sleep. Sleep Med Rev 2002; 6: 29-44. 